ESJ Natural/Life/Medical Sciences

\title{
The Relationship Between Apache Ii Score And Nurses' Occupational Stress In Icu
}

\author{
Pei-Ying Jao (RN, MSN) \\ Yuanshan Branch, Taipei Veteran General Hospital, Taiwan (ROC) \\ Noreena Yi-Chin Liu (PhD) \\ University of Southampton, United Kingdom \\ Hsiu-Lan Wu (RN, MSN) \\ Yuanshan Branch, Taipei Veteran General Hospital, Taiwan (ROC) \\ Cheng-Hui Chou (RN, MSN,PhD) \\ Assistant Professor, School of Nursing, National Taipei University of \\ Nursing and Health Sciences, Taiwan (ROC) \\ Kuan-Chia Lin (PhD) \\ Professor, Institute of Hospital and Health Care Administration, National \\ Yang-Ming University
}

Doi:10.19044/esj.2021.v17n29p19

Submitted: 18 March 2021

Copyright 2021 Author(s)

Accepted: 06 July 2021

Under Creative Commons BY-NC-ND

Published: 31 August 2021 4.0 OPEN ACCESS

Cite As:

Jao P-Y., Yi-Chin Liu N., Wu H-L., Chou C-H. \& Lin K-C. (2021). The Relationship Between Apache Ii Score And Nurses' Occupational Stress In Icu. European Scientific Journal, ESJ, 17(29), 19.

https://doi.org/10.19044/esj.2021.v17n29p19

\begin{abstract}
Occupational stress remains one of the major concerns among nurses working in ICU, which affects the individuals as well as the quality of patient care. This paper focuses on investigating the correlation between the ICU patient severity and the nurses' occupational stress. The paper also identifies a number of occupational stress factors. A total of 81 ICU nurses from the teaching hospitals in Eastern Taiwan have been selected to take part in this study through purposive sampling. Cross-sectional study was adopted for this study and interviews were done through a structured questionnaire. The data was collected using the APACHE II scale and the Nursing Stress scale. The result of the correlation analysis between disease severity and occupational stress was found to be insignificant ( $p>.05)$. The regression model analysis shows that patient severity plays a moderation effect between nurses'
\end{abstract}


characteristics and occupational stress. The results of this study could serve as reference to policymakers and nursing administrators to create a supportive environment. Policy changes to improve the nurses' working conditions were also proposed in this paper.

Keywords: Intensive Care, Disease Severity, Nurses’ Occupational Stress

\section{Introduction}

The demand for nurses has been increasing around the world as a result of global issues such as global climate change, aging population, and the complexities of modern living. Due to the inadequate number of nurses to meet the demand, the nursing shortage has increased the workload significantly for those who are currently on the job. Nursing is a highly-stressed profession which requires specialist knowledge and skills, especially for those who work with severely ill patients in Intensive Care Units (ICUs). ICU nurses are recognized as advanced clinicians who have to demonstrate the ability to operate medical equipment and adopt life-saving techniques to help patients in critical conditions.

According to the Chung Shan medical report in 2002, the stress level experienced among nurses comes from a patient's illness level and other related work (Shih \& Chou, 2002). In general, people with serious illnesses might require complex medical equipment and specialized treatments (Cheung et al., 2019). In ICUs, complete caregiving is practised and nurses must perform physically demanding tasks such as turning patients in bed, moving patients, as well as cleaning them.

A limited workforce and high number of patients forces nurses to work faster to complete their tasks within their shift hours. These factors constitute a significant physical and psychological burden to them (Chou, Li, \& Hu, 2014). Due to the tough workplace ecology and the demanding nature of nursing environments, setbacks can elicit more negative physical and psychological responses among nurses. Therefore, their intentions to stay in their job declines. As a consequence, a vicious cycle of nursing workforce deficiency is formed.

In Taiwan, a study revealed that $21.2 \%$ of nurses with sleep disorders experienced a medium to severe anxiety level (Lin, Chueh, \& Lin, 2015). This cumulative stress will threaten nurses' health. Therefore, actions have to be taken to help reduce nurses' occupational stress.

ICU practices are often filled with heavy workload situations (Chang, Lu, \& Lin, 2010). This study aims to examine the association between patients' disease severity and occupational stress among ICU nurses. Its findings can serve as useful resources for quality management, policymaking, and on-the-job training. The results of the study provide measures that will 
improve the working environment, work satisfaction, and other related policies for nursing.

\section{Related Work}

Nursing is an essential part of the healthcare system (Lin et al., 2020). Apart from offering medical expertise, they also have to assist in managing complicated relationships involving patients, their family members, and other medical personnel. Due to the complexity in their work, nursing is generally recognized as one of the most challenging and stressful professions (Lazarus, 2000).

Since patient-centered medical care is now very common, research is done in attempt to fully understand the effects of medical and nursing care on patients. To rate the medical and nursing care quality, each patient's condition and situation needs to be taken into account. This includes features such as psychology and physiology (Lin, et al., 2020), education, living quality, relationships with family, safety, satisfaction, access to and use of health services, and the hospital's mechanisms for disease control.

Although nursing care plays an important role, the quality of care can be affected by many factors including the organizational support within hospitals, occupational stress, occupational burnout, absenteeism, resignation intention, shift rotation, and occupational infections. Each of these may negatively impact quality of care.

\section{ICU Nursing in Hospitals}

According to statistics from the Taiwan Ministry of Health and Welfare (2019), the occupancy rate of hospital beds in the country due to acute illness was 65.2\% in 2016 and 70.15\% in 2019. Notably, this rate has increased steadily since then. Also, the number of patients with acute illnesses is on the rise. Therefore, it is vital to quickly quantify the severity of illness so that treatments can be provided for those in need in the ICUs, especially during crisis such as the COVID-19 pandemic (Sen-Crowe et al., 2021).

The COVID-19 global pandemic poses challenges for healthcare systems around the world. Nurses in ICUs are well-trained with a professional obligation to provide high quality care, despite the potential to become infected (Lord et al., 2021). ICU nurses must remain on high alert at all times to appropriately handle changes in patients' conditions. Also, nurses must consider the feelings of their patients and their family members. Consequently, nursing staff often feel stressed (Tilda, 2006). Furthermore, shift work, overtime work, and self-expectations in professional development often contribute to the accumulation of stress over long periods of time. This can affect nurses' physical health, induce fatigue, cause them to lose concentration, and even make mistakes. They may eventually lose passion for 
their work, experience burnout, and consider resigning which worsens the nursing shortage situation. One way to solve the nursing shortage is to help nurses to relieve stress in an appropriate and timely manner.

\section{Nurses' Occupational Stress}

There are various reasons that contribute to occupational stress in nursing professionals. The primary factor is the outcome-human interactions in nursing which involve an individual's work environment, work climate, and work characteristics. Personalities and adaptability also affect occupational stress. For example, resilience can alter an individual's stress. Other factors that affect occupational stress are safety at work, organizational management styles, interpersonal relationships in the workplace, and welfare systems (Lin, Chueh, \& Lin, 2015).

As nurses' self-expectations and the public's expectations towards their performance increase, occupational stress can be heightened. Chronic occupational stress may have a negative impact on the mental aspects of nurses' quality of life, the quality of care provided, and patient safety (Ho et al., 2010).

Benoliel et al. (1990) developed a Nurse Occupational Stressor Scale (NOSS), which uses questionnaires to evaluate the stress levels of nurses. This questionnaire analyzes the social functions derived from stress responses in various nursing scenarios (Benoliel et al., 1990). It consists of an individual's professional knowledge and competencies, environmental needs, role conflicts, role requirements, communication with colleagues, and pressures from institutional bureaucracies. The scale helps to reveal the conflicts between professional and personal duties and physiological and psychological health responses (Benoliel et al., 1990).

Professor Tsai, from the Fu Jen Catholic University, used the NOSS to expose four stress dimensions, namely: personal responses, job concerns, competencies, and the inability to complete personal duties (Tsai \& Chan, 1996). NOSS contains 43 items score using a 9-point Likert scale. A higher score denotes higher levels of occupational stress.

The occupational stressors of nurses are multidimensional. Without appropriate prevention and relief, nurses may experience burnout as their stress levels increase. Burnouts not only affect nurses' physical and mental health significantly, the patient's safety and nursing care quality can also be impacted. Therefore, reducing occupational stress among nurses is crucial to ensure high quality medical care.

The person-environment fit model proposed by French, Roger, and Cobb in 1974 (French et al., 1974) suggests two causes of occupational stress: 1. An individual's lack of satisfaction in terms of his or her work environment; 2. An individual's lack of ability to meet the work environmental requirements 
of his or her profession. Occupational stress among nursing staff varies depending on the workplace. Existing research studies have shown that the factors affecting occupational stress among nurses include age, marital status, job seniority, shift work, ranking, educational level, number of patients under one's care, self-rated mental and physical health, and intensive-care-related training (Tsutsumi et al., 2001).

\section{The Effects of Illness Severity on Nurses}

In 1863, Florence Nightingale classified patients into the following four illness severity levels, namely: extremely serious, serious, not serious, and healthy. This classification system was used to determine priorities for caregiving and management. However, the Nightingale classification is too simplistic to be used in today's advanced and complex medical environment.

Therefore, a more structured disease severity evaluation is crucial. The most commonly used disease severity evaluation instrument is the Acute Physiology and Chronic Health Evaluation (APACHE II) (Knaus et al., 1981), which contains three parts. The first part comprises of 12 acute physiological descriptors items which are scored 24 hours after the patient is admitted to the ICU. These 12 items include average arterial pressure, heart rate, respiration rate, oxygenation (A-a $\mathrm{O} 2$ difference or $\mathrm{PaO} 2$ ), arterial blood $\mathrm{pH}$, serum sodium, serum potassium, serum creatinine, hematocrit, white blood cell count, body temperature $\left({ }^{\circ} \mathrm{C}\right)$, and Glasgow coma score. The second part refers to the age score. This means that the older the patient, the higher the score. Patients aged less than 44 years old score 0 , while those aged above 75 score 6 . The third part refers to the chronic health score. This implies that those with a history of severe organ dysfunction or immune dysfunction are scored between 2 and 5 . The scores of all three parts vary between 0 and 71. The higher the overall score, the more serious the illness of the patient. Thus, this results to a higher likelihood of mortality rate (Knaus et al., 1985). APACHE II is a common evaluation instrument used in a variety of designs. For example, APACHE II score can be used to predict the probability of posttraumatic stress disorder in survivors of critical illness (Battle et al., 2017). In 2016, the University of Sarajevo presented a research study which used predictive value of Simplified Acute Physiology Score (SAPS II) and APACHE II scoring systems for patients' outcome in a medical intensive care unit (Godinjak et al., 2016).

Existing research has shown that the most common source of occupational stress for nurses comes from their colleagues or their personal assignments, while the second most common source is workload. The most intense occupational stress type occurs when a patient's condition deteriorates while a medical doctor is unavailable. Overall, ICU nurses tend to experience greater occupational stress than outpatient clinic nurses. Nurses' self-rated 
workload scores are positively related to patients' APACHE II scores and the frequency of changes in inpatient care settings (Chen, 1997).

In health care environments, inter-departmental communication and negotiations are necessary, and consensus must be reached so that medical professionals can collaborate and care for patients to the best of their ability. ICU environments are relatively enclosed and complicated. Domestic and overseas studies have shown that the more serious an ICU patient's illness is, the higher the occupational stress among corresponding nurses (Carayon \& Carla, 2007). Many nurses consider that a higher number of patients and higher severity of illness denote more work, and an increase in nursing workload increases their occupational stress (Hussein, Aniza, \& Taufik, 2012). Although many studies have investigated occupational stress among nurses, few studies have examined correlations among patient illness severity, occupational stress among ICU nurses, and negative care outcomes. Therefore, the present study investigated the associations between these factors to fill the research gap.

\section{Research Methodology}

The research used a cross-sectional method. Data was collected through structured questionnaires. Purposive sampling was adopted in three regional hospitals in Eastern Taiwan. The participants were nurses who had worked in ICUs with at least three months of experience in internal medicine or surgery departments. Management staff, such as deputy head nurses or those from higher positions, were excluded in this study.

The sample size was calculated using G*POWER 3.0 with a Cronbach's $\alpha$ of 0.05 (Faul et al., 2007). The effective size was calculated using the method proposed by Chen (2007) with a Cronbach's $\alpha$ of 0.3. The effective sample size was obtained with 81 participants. The power for regression analysis was calculated as $\alpha=0.85$.

\section{Research Design}

This study used structured questionnaires to collect data on the demographics of nurses, occupational stress among nurses, and patient illness severity. The three questionnaires consist of Nurses' Demographic Survey, Nurse Occupational Stress Questionnaire (NOSS), and Patient Illness Severity (APACHE II).

\section{a. Nurses’ Demographic Survey}

The demographic survey for nurses was developed based on a literature review conducted by the researchers of this study. The questionnaires were used to collect data on each participant's personal information such as gender, age, marital status, seniority, educational level, 
number of patients, self-rated physical and mental conditions, professional training, job title, in-service training, ranking, shift type, job rotation, license type, division of employment, and hospital level of care. The respondents were instructed to check the options that best describe their situation.

\section{b. Nurse Occupational Stress Questionnaire (NOSS)}

The nurse occupational stress questionnaire used the Mandarintranslated Nurse Occupational Stressor Scale (NOSS).

The questionnaire is used to assess the stress experienced by nurses at work based on 43 items. The items are divided into four dimensions with a factor loading cutoff of 0.4 , namely: personal responses (16 items), job concerns (13 items), competencies (11 items), and inability to complete personal duties (3 items).

The job concern dimension relates to issues arising from caring for patients, communicating with doctors and patients' family members, nurses' professional expectations, and evaluating medical system operations. Personal responses refer to nurses' negative physical and psychological responses to their work. Examples of the response are "I think I am not emotionally stable", "I once felt tired", and "I feel discouraged". Competencies refer to nursing staff members' satisfaction in fulfilling their duties and their professional capabilities. For example, "I cannot complete nursing work as expected" and "I can complete nursing work successfully within my capacity". Inability to complete personal work relates to the overwhelming workload which involves daily tasks which can be relatively easy but exhausting. It could be viewed as obstructive and also add to the stress responses of individuals triggered by interactions with their environments. The three items corresponding to inability to complete personal duties are related to the conflict between insufficient time and nursing staff members' self-expectations. These options for the questionnaire are "there is not enough time to complete what one has to do", "there is not enough time", and "it is hard to help the doctor understand my point”.

\section{(1) Scoring}

The 43 items mentioned above are rated using a 9-point Likert scale ranging from 0 (lowest) to 8 (highest). Higher scores denote more significant stress, except for the competencies dimension where the items reflect positive stress-related emotions. Accordingly, higher scores denote lower levels of stress. Therefore, the items in this dimension are rated inversely. This means that a score of zero is converted into a score of 8 and vice versa (Tsai, 1993). 


\section{(2) Validity}

This scale reflects nurses' stress conditions over the preceding week. In a validation study, occupational stress among 511 nurses in a medical centre in Taiwan was investigated. The total variance explained by the four dimensions discussed above was $80.1 \%$. Regarding internal consistency for each variable, the Cronbach's $\alpha$ was greater than 0.84 . This indicates that the questionnaire accurately reflects stress among nurses in Taiwan (Tsai, Chen, \& Wang, 1996).

\section{(3) Reliability}

The Nurse's Occupational Stress Questionnaire was translated into Mandarin by Tsai (Tsai, 1993). A total of 39 items had a Pearson's coefficient of 0.7 or above. Eight items did not reach 0.7. The Mandarin version of the test was revised and retested on nursing personnel $(\mathrm{N}=138)$. The overall Cronbach's $\alpha$ of the questionnaire was 0.93 , indicating high internal consistency (Tsai, 1993). Subsequently, data were collected from 41 nurses and used to analyze each dimension. For each dimension, Cronbach's $\alpha$ was between 0.79 and 0.95 . The overall internal consistency (Cronbach's $\alpha$ ) of the questionnaire was 0.93 . This suggests high short-term stability and internal consistency, which leads to high reliability (Tsai, Chen, \& Wang, 1996).

\section{c. Patient Illness Severity (APACHE II)}

This study used APACHE II to evaluate patient illness severity. APACHE II rates patient illness severity based on 12 items, namely: body temperature $\left({ }^{\circ} \mathrm{C}\right)$, heart rate, average blood pressure, respiration rate, oxygen saturation, arterial blood $\mathrm{pH}$, serum sodium, serum potassium, serum creatinine, hematocrit, white blood cell count, and Glasgow coma score (including chronic conditions and age). The total scores range from 0 to 71 . The more severe the patient's illness, the higher the score. Subsequently, this leads to a likelihood of increased mortality rate (Knaus et al., 1985).

In the United States, Knaus et al. (1981) correlated the APACHE II scores and survival of 5,815 ICU patients in 13 medical centers. A positive correlation between APACHE II scores and ICU patients' mortality was reported, with a scale reliability and validity of $87 \%$ (Knaus, Draper, \& Wagner, 1985; Knaus et al., 1981).

\section{Data Processing and Analysis}

SPSS 2.0 suite was used in this study for data filing and analysis. Descriptive statistical analysis was performed on the nurses' demographic information, occupational stress questionnaire scores, and APACHE II scores. Pearson correlation and Spearman rank correlations were adopted to test for correlations between variables. Suggestions from the study of Baron and 
Kenny (1986) were considered in order to test whether a patient's illness severity exerted any mediating effects. The analysis further examined the link between occupational stress among nurses and patient illness severity with a regression model.

\section{Results}

This study tested three hypotheses:

1. Correlation between ICU Nurses' Demographics and Occupational stress (see Appendix A);

2. Associations between Patient Illness Severity and Nurses' Occupational stress;

3. Analysis of the Modulating Effect of Patient Illness Severity on Nurses' Occupational Stress (see Appendix B).

\section{Correlation between ICU Nurses' Demographics and Occupational Stress}

The nurses' demographic results for the 81 participants are shown in Appendix A. Most nurses recruited for this study were women within the age range of 32 years (approximately 90\% were under 30 years old). Approximately $70 \%$ of the participating nurses had obtained a bachelor's degree or higher, while $53 \%$ were single. Approximately $90 \%$ were contracted nurses with an average number of years of seniority of 8.37. The most common ranking was N2 (70\%), and more than 90\% had not undergone any in-service training. Regarding self-rated health status, approximately $73 \%$ rated themselves as being of average health, while $53 \%$ rated themselves to be less healthy today than the previous year (53\%).

The nurses' occupational stress questionnaire results revealed that the personal responses dimension had the highest average score per item (mean (M) score was 64 , with a standard deviation (SD) of 20.15, followed by selfrated competencies for nursing work $(\mathrm{M}=43.48, \mathrm{SD}=7.83)$, and inability to complete personal work $(\mathrm{M}=11.26, \mathrm{SD}=6.30)$. Job concerns $(\mathrm{M}=3.68$, SD $=13.42$ ) had the lowest average score per item. These results show that the overall stress among ICU nurses was at a medium-high level (Table 1).

Table 1. Nurse Occupational Stress Analysis $(\mathrm{N}=81)$

\begin{tabular}{|c|c|c|c|c|c|c|}
\hline Dimension & $\begin{array}{c}\text { Number of } \\
\text { questions }\end{array}$ & $\begin{array}{c}\text { Variable } \\
\text { range }\end{array}$ & $\mathrm{M}$ & $\mathrm{SD}$ & $\begin{array}{c}\text { Range of } \\
\text { obtained } \\
\text { score }\end{array}$ & $\begin{array}{c}\text { Average } \\
\text { score } \\
\text { per item }\end{array}$ \\
\hline $\begin{array}{c}\text { Nonproductive } \\
\text { reactions }\end{array}$ & 16 & $0-128$ & 64.22 & 20.15 & $12-106$ & 4.01 \\
\hline $\begin{array}{c}\text { Professional } \\
\text { concerns }\end{array}$ & 13 & $0-104$ & 47.78 & 13.42 & $2-74$ & 3.68 \\
\hline $\begin{array}{c}\text { Satisfactory } \\
\text { responses }\end{array}$ & 11 & $0-88$ & 43.48 & 7.83 & $16-58$ & 3.95 \\
\hline Falling behind & 3 & $0-24$ & 11.26 & 6.30 & $0-24$ & 3.75 \\
\hline
\end{tabular}

Note: Average score per item $=$ mean score $/$ number of questions 
This correlation analysis between nurses' occupational stress scores and their demographics produced results as shown in Table 2 . Subsequently, the researchers investigated correlations between the four dimensions of nurses' stress and demographics, namely: personal responses, job concerns, competencies, and inability to complete personal work. Pearson correlation analysis was conducted on the continuous variables, whereas Spearman rank correlation was used for the categorical variables.

Table 2. Correlations between Nurses’ Demographics and Occupational stress ( $\mathrm{N}=81)$

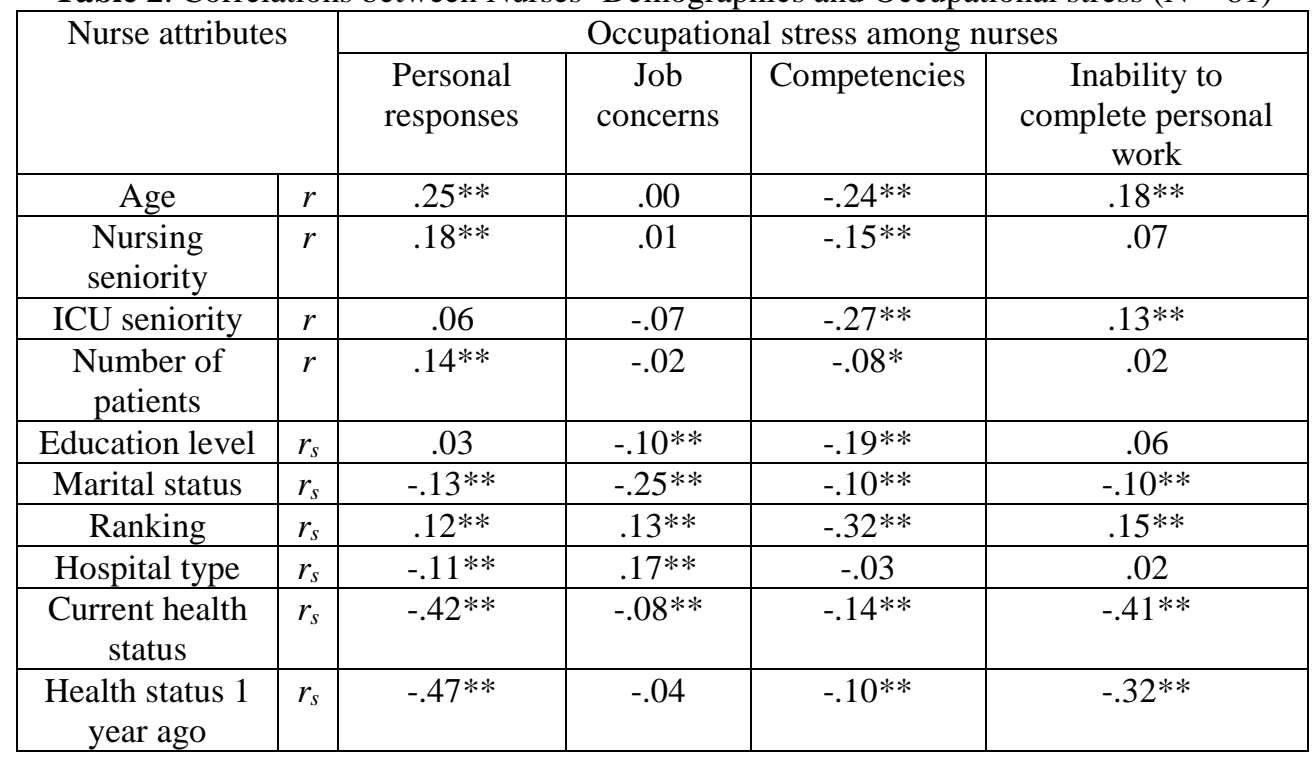

The personal response dimension was positively correlated with age, work seniority, number of patients, and ranking $(\mathrm{p}<.01)$. This suggests that the older the nurse, the more patients they have in their care. On the other hand, the higher the nurse's ranking, the more negative their physical and psychological responses. The personal responses dimension was negatively correlated with marital status, hospital level, current health status, and health status in the previous year.

This finding indicates that nurses who are single or working at a lowerlevel hospital, and those with poor health were more likely to have more negative physical and psychological responses. Ranking, hospital level, and job concerns were positively correlated with one another $(\mathrm{p}<.01)$. For the nurses in this study, being more highly ranked involves more responsibility. In addition to the lack of sufficient time to provide adequate clinical care, more highly-ranked nurses experience higher occupational stress as they have to do more communication with patients, their family members, and doctors as compared to lower rank nurses.

Job concerns, educational level, marital status, and current health status were negatively correlated to each another $(\mathrm{p}<.01)$. Therefore, nurses 
who have a lower education level or are unmarried and consider themselves less healthy tend to experience greater stress than their counterparts. This is due to communication problems, professional expectations, and a lack of familiarity with the medical system. In terms of nurses' demographics and their self-rated stress levels for each dimension, the results show that nurses who are single, older, having a lower ICU seniority, lower ranking, and are in poor health are more likely to experience greater occupational stress than their counterparts.

\section{Association between Nurses' Occupational Stress and Patient Illness Severity}

During the research period, 798 people were admitted to ICUs. These patients' APACHE II scores were between 0 and $48(\mathrm{M}=19.44, \mathrm{SD}=8.79)$. The average length of stay in the ICU was 11 days $(S D=10)$. Patient illness severity was low. A total of 75 patients experienced the negative care outcome of death (9.4\%). Also, 331 experienced British Standards Institution (BSI) (3.9\%), and one experienced Ventilator-associated Pneumonia (VAP) infection (0.1\%). The average ICU length of stay is 10.76 days. This is shown in Table 3.

Table 3. Patient with negative care outcome $(\mathrm{N}=798)$

\begin{tabular}{|c|c|c|}
\hline Negative care outcome & Number of people & Percentage ( \% ) \\
\hline No & 691 & 86.6 \\
\hline Yes & 1 & 0.1 \\
\hline VAP & 31 & 3.9 \\
\hline BSI & 75 & 9.4 \\
\hline Death & \multicolumn{2}{|}{} \\
\hline
\end{tabular}

Spearman correlation was used to analyze the correlation coefficient between nurses' occupational stress and patients' illness severity. The results showed a lack of statistical significance in terms of the correlation between the four occupational stress dimensions (personal responses, job concerns, competencies, and inability to complete personal work) and patient illness severity or negative care outcomes $(\mathrm{p}>0.05)$.

This finding suggests that there were no significant correlations between occupational stress among nurses, patient illness severity, and negative care outcomes.

\section{Analysis of the Modulating Effect of Patient Illness Severity on Nurses' Occupational Stress}

The total score for occupational stress among nurses revealed no significant correlation with patient illness severity. Nonetheless, it was unclear whether patient illness severity exerts any modulating effect on occupational 
stress among nurses. Therefore, this study used the regression model suggested by Baron and Kenny (1986) to test whether patient illness severity modulates nurses with different attributes stress. In the regression equation, $\mathrm{X} 1$ denotes nurses' characteristics and $\mathrm{Y}$ denotes the four dimensions of occupational stress (personal responses, job concerns, competencies, and inability to complete personal work).

Modulating variable X2 represents APACHE II scores. X1, X2, and the product of standardized $\mathrm{X} 1$ and $\mathrm{X} 2(\mathrm{ZX} 1 \times \mathrm{ZX} 2)$ were the inputs for the regression analysis to predict the value of $Y$. If the regression coefficient of the interaction was statistically significant, then $\mathrm{X} 2$ will be the modulating variable that affects the direction or intensity of the relationship between X1 and Y. This is shown in Figure 1.

$\mathrm{X} 2$

APACHE II

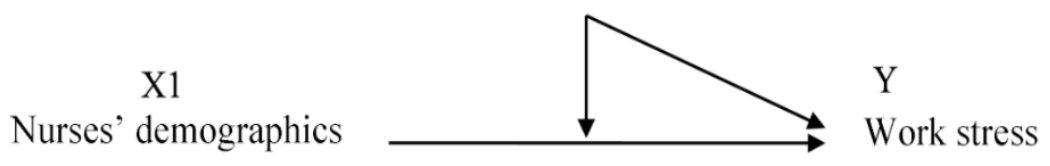

Figure 1. Modulating Effect of Patient Illness Severity on Occupational Stress among Nurses with Different Attributes

The results of the nurse occupational stress questionnaire are shown in Appendix B within the four dimensions The analysis results revealed that when predicting occupational stress, the interaction between APACHE II scores and nurses' demographics achieved statistical significance (nurses' demographics $\times$ APACHE II scores; $\mathrm{p}<.01$ ).

Patient illness severity affected the stress level of nurses. The nurse's situation such as age, marital status, number of patients, job seniority, ICU seniority, ICU training, hospital level, type of shift, and current health status will also affect their stress level.

Patient illness severity exerted a clear modulating effect to the occupational stress among nurses. Instead of directly influencing nurses' occupational stress, patient illness severity modulated the level of stress among nurses with different attributes.

\section{Discussion}

The three research objectives can be discussed in two fields, namely:

1. Correlation between ICU Nurses' Attributes and Occupational stress

2. Correlation between Nurses' Occupational stress and Patient Illness Severity.

Firstly, it can be established that the nurses' communication problems related to job roles and their professional expectations are correlated to their 
marital status, ranking, and job concerns. For example, married nurses are more likely to find ways to relieve occupational stress than unmarried nurses. Furthermore, N2-ranked nurses who are single are generally younger, of lower seniority, and are less mature in professional knowledge and skills. Furthermore, they cannot analyze and solve problems to the same degree of the senior colleagues. Hence, they tend to experience more occupational stress.

Secondly, patient illness severity is expected to affect a nurse's workload. For example, inpatients in veterans' hospitals are more than 80 years old, mostly single, living in the hospital, have various chronic diseases, and require full assistance in their daily lives. Such patients also require complicated medical treatments and comprehensive care from nurses.

\section{Correlation between ICU Nurses' Attributes and Occupational Stress}

The overall stress levels of the nurses researched in this study was at a medium-high level, and the most major source of stress was competencies and personal responses. These findings suggest that nurses lack confidence in their personal competencies. Furthermore, nurses have considerable mental and physical burdens because of insufficient work experience and skills and there is a shortage of nursing personnel. This study also indicates that the marital status and job concerns of nurses are correlated. Most single nurses are young, of low seniority, and less mature in terms of professional knowledge and skills. ICU work requires nurses to maintain concentration for long periods of time. Therefore, administering invasive treatments may cause excessive physical and mental stress for newly qualified nurses. This is partially because they lack sufficient experience and confidence. Nevertheless, the physical and mental burden will fade as nurses gain more experience and knowledge.

Research in Taiwan showed that hiring part-time nurses for routine nursing work can reduce occupational stress among full-time nurses due to the reduction in workload (Tsai, Chen, \& Wang, 1996). Understaffing in clinical nursing, heavy workloads, and large amounts of overtime hours are fairly common nowadays. In addition, nursing practice environments are not getting enough support (Higazee, Rayan, \& Khalil, 2016). Basic nursing work is timeconsuming and can prevent nurses from performing their more advanced professional duties. Clinical nursing work is complex, and there is a lack of clear distinction between professional and non-professional nursing work. Consequently, nurses spend many of their working hours performing nonprofessional tasks. Also, many nurses develop sleep disorders and health problems such as unrecoverable fatigue because of shiftwork (Chou, $\mathrm{Li}, \& \mathrm{Hu}$, 2014). 


\section{Correlation between Nurses' Occupational Stress and Patient Illness Severity}

Patient illness severity in this study is similar to the study of Chen (2007). The average occupational stress questionnaire score in the present study was 3.84, while the occupational stress index of 138 nursing staff members from three medical centers in Taiwan was 3.15 (Tsai, Chen, \& Wang, 1996). Although these two occupational stress levels are similar, no significant correlation was found between nurses' occupational stress and patient illness severity. However, the modulating effect of patient illness severity on occupational stress among nurses was significant. Some studies have shown that nurses working in regional hospitals experience higher stress compared to nurses working in local hospitals. This is because the two hospital types admit different numbers of patients with different levels of illness severity, and they also use different medical equipment. In addition, these two hospital types require different professional knowledge and technology. The level of sensitivity to patient safety also varies (Chang, Chen, \& Chen, 2016). Consequently, nurses in these two hospital types are likely to experience different stress levels. For example, inpatients in veterans hospitals are more than 80 years old on average, mostly single, living in the hospital, have various chronic diseases, and require full assistance in their daily lives. Such patients also require complicated medical treatments and comprehensive care from nurses. Due to the lack of a high-precision, physiological surveillance technology in regular wards, and manpower, some patients who require close monitoring may be sent to ICUs even though their illnesses are not severe. This practice can add to the burden of ICU nurses. Due to nursing shortages, nurses commonly have heavy workloads which requires them to work for hours overtime. The distinction between professional and nonprofessional work in the nursing domain is still lacking. As a result, nurses spend many of their working hours performing nonprofessional tasks.

\section{Conclusion}

This study used a cross-sectional design that employed questionnaires to evaluate nurses' occupational stress. Notably, stress is dynamic, especially in ICUs.

These insights indicate that stress causes physical and mental fatigue among nurses and is multidimensional and interactive. The social, cultural, and psychological aspects must be considered in order to improve the working environment. Thus, this paper offers the following suggestions:

1) Maintain a reasonable patient-nurse ratio and provide reasonable salaries for nurses;

2) Provide nurses with appropriate care and assistance according to each nurse's personality and characteristics; 
3) Cultivate a friendly organizational culture and workplace;

4) Avoid asking nurses to move heavy patients or objects;

5) Managers should routinely visit their nursing staff to understand the effects of work-related stress on staff.

The implementation of measures based on these suggestions could help improve well-being and job satisfaction among clinical nurses by reducing their occupational stress levels.

This study used the convenience sampling approach. The sample size was small, and participants were recruited only from Eastern Taiwan. The analysis results have limited generalizability. However, it is argued that this is enough to examine nurses' occupational stress issues and identify several problems such as limited support, workload, and patient illness levels.

\section{References:}

1. Battle, C. E., James, K., Bromfield, T., \& Temblett, P. (2017). Predictors of post-traumatic stress disorder following critical illness: A mixed methods study. Journal of the Intensive Care Society, 18(4), 289-293.

2. Baron, R., \& Kenny, D. A. (1986). The moderator-mediator variable distinction in social psychological research: Conceptual, strategic, and statistical considerations. Journal of Personality and Social Psychology, 51(6), 1173-1182.

3. Benoliel, J., Mc Corkle, R., Georgiadou, F., Denton T, \& Spitger A. (1990). Measurement of stress in clinical nursing. Cancer Nursing, 13(4), 221-228.

4. Carayon, P., \& Gurses, A. (2007). A human factors engineering conceptual framework of nursing workload and patient safety in intensive care units. Intensive and Critical Care Nursing, 21(5), 284301.

5. Cheung, S., Spaeth-Rublee, B., Shalev, D., Li, M., Docherty, M., Levenson, J., \& Pincus, H. A. (2019). A Model to Improve Behavioral Health Integration into Serious Illness Care. Journal of Pain and Symptom Management, 58(3), 503-514.e1. https://doi.org/10.1016/j.jpainsymman.2019.05.017

6. Chang, H. L., Lu, M. S., \& Lin, C. F. (2010). Factors Related to New Nursing Staff Turnover Rates. The Journal of Health Science. 12(3), 161-172

7. Chang, T. F., Chen, C. K., \& Chen, M. J. (2016). A Study of Demographic Traits, Job Stress, Job Satisfaction, and Turnover Intention Among Nurses Working in Different Types of Hospital-The Case of Six Local Community Hospitals and Four Metropolitan Hospitals. Cheng Ching Medical Journal, 12(2), 28-34. 
8. Chou, L., Li, C., \& Hu, S. (2014). Job stress and burnout in hospital employees: Comparisons of different medical professions in a regional hospital in Taiwan. British Medical Journal, 4(2), 1-7.

9. Faul, F., Erdfelder, E., Lang, A. G., \& Buchner, A. (2007). G*Power 3: A flexible statistical power analysis program for the social, behavioral, and biomedical sciences. Behavior Research Methods, 39(2), 175-191.

10. French, J., Rogers, W., \& Cobb, S. (1974). Adjustment as a personenvironment fit. In: Coelho, G. V., Hamburg, D. A. and Adams, I. F. (Eds.) Coping and Adaptation: Interdisciplinary Perspectives, New York, Basic Books, 316-333.

11. Godinjak, A., Iglica, A., Rama, A., Tančica, I., Jusufović, S., Ajanović, A., \& Kukuljac, A. (2016). Predictive value of SAPS II and APACHE II scoring systems for patient outcome in a medical intensive care unit. Acta Medica Academica, 45(2), 97-103.

12. Goetz, N., Wald, A., \& Freisinger, E. (2021). A person-environmentfit-model for temporary organizations - Antecedents for temporary working settings. International Journal of Project Management, 39(1), $1-9$.

13. Higazee, M. Z. A., Rayan, A., \& Khalil, M. (2016). Relationship between Job Stressors and Organizational Support among Jordanian Nurses. American Journal of Nursing Research, 4(3), 51-55.

14. Ho, H. C., Chang, S. H., Tsao, J. Y., Chang, M. F., Chen, Y. H., Yang, T. (2010). The Relationship between Job Stress and PhysicalMental Health among Hospital Staff. Chinese Journal of Occupational Medicine, 17(4), 239-252.

15. Lazarus, R. S. (2000). Toward better research on stress and coping. American Psychologist, 55(6), 665-673.

16. Lin, C. F., Lai, F. C., Huang, W. R., Huang, C. I., \& Hsieh, C. J. (2020). Satisfaction with the Quality Nursing Work Environment among Psychiatric Nurses Working in Acute Care General Hospitals. Journal of Nursing Research, 28(2).

17. Lin, Y. H., Chueh, K. H., \& Lin, Y. N. (2015). Work Stress and Anxiety among Clinical Female Nurses with Sleep Disturbance. Vancouver General Hospital Nursing, 32(2), 154-165.

18. Lord, H., Loveday, C., Moxham, L., \& Fernandez, R. (2021). Effective communication is key to intensive care nurses' willingness to provide nursing care amidst the COVID-19 pandemic. Intensive and Critical Care Nursing, 62.

19. Knaus, W. A., Wagner, D. P., Draper, E. A., Lawrence, D. E., \& Zimmerman, J. E. (1981). The range of intensive care services today. The Journal of the American Medical Association, 246(23), 2711- 
2716.

20. Knaus, W. A., Draper, E. A., Wagner, D. P., \& Zimmerman, J. E. (1985). APACHE II: A severity of disease classification system. Critical Care Medical, 13(10), 818-829.

21. Ministry of Health and Welfare (2019). Number of Registered Medical Personnel in Hospitals, Clinics and Other Medical Care Institutions, Taiwan Area. Retrieved June 30, 2019. $<$ https://dep.mohw.gov.tw/dos/cp-1735-3244-113.html >.

22. Sen-Crowe, B., Sutherland, M., McKenney, M., \& Elkbuli, A. (2021). A Closer Look Into Global Hospital Beds Capacity and Resource Shortages During the COVID-19 Pandemic. Journal of Surgical Research, 260, 56-63. https://doi.org/10.1016/j.jss.2020.11.062

23. Shih, F. F., \& Chou, C. F. (2002). A Study on Job Stress and Coping Behaviors of Nurses in Drug Addictive Wards. Chung Shan Medical Journal. 13(2), 197-208.

24. Tilda, S. (2006). A Nurse's Story: Life, Death, and in-between in an Intensive Care Unit. Canada: McClelland \& Stewart.

25. Tsai, S. L. (1993). The Chinese nurse stress in Taiwan, Republic China. Issues in Mental Health Nursing, 14(3), 275-285.

26. Tsai, S. L., Chen, M. L., \& Wang, BW. (1996). Related Factors of Nurse Work Stress in a Medical Center. Vancouver General Hospital Nursing, 13(3), 263-269.

27. Tsutsumi, A., Kayaba, K., Theorell, T., \& Siegrist, J. (2001). Association between job stress and depression among Japanese employees threatened by job loss in a comparison between two complementary job stress models. Scandinavian Journal of Work Environmental and Health. 27(2), 146-153.

Appendix A. Nurses' Socio-demographic variables ( $\mathrm{N}=81)$

\begin{tabular}{|c|l|l|l|l|}
\hline Class & $\begin{array}{l}\text { Number of } \\
\text { people }\end{array}$ & $\begin{array}{l}\text { Percentage } \\
(\%)\end{array}$ & Mean & $\begin{array}{l}\text { Standard } \\
\text { deviation }\end{array}$ \\
\hline Gender & & & & \\
\hline Male & 1 & 1.2 & & \\
\hline Female & 80 & 98.80 & & \\
\hline Age & & & 31.80 & 5.38 \\
\hline Educational level & & & & \\
\hline Junior college & 24 & 29.60 & & \\
\hline University & 57 & 70.40 & & \\
\hline Marital status & & & & \\
\hline Single & 43 & 53.10 & & \\
\hline Married & 38 & 46.90 & & \\
\hline Number of patients & & & & \\
\hline Less than two & 4 & 4.90 & & \\
\hline Three & 60 & 74.10 & & \\
\hline
\end{tabular}




\begin{tabular}{|c|c|c|c|c|}
\hline More than four & 17 & 21.00 & & \\
\hline \multicolumn{5}{|l|}{ ICU training experience } \\
\hline No & 8 & 9.90 & & \\
\hline Yes & 73 & 90.10 & & \\
\hline Years of nursing seniority & & & 8.37 & 4.97 \\
\hline Years of ICU seniority & & & 5.88 & 4.08 \\
\hline \multicolumn{5}{|l|}{ Employment status } \\
\hline $\begin{array}{ll}\text { nurse } & \text { Government-employed } \\
\end{array}$ & 7 & 8.65 & & \\
\hline $\begin{array}{l}\text { Government-employed } \\
\text { registered nurse }\end{array}$ & 3 & 3.70 & & \\
\hline Contract nurse & 70 & 86.45 & & \\
\hline \multicolumn{5}{|l|}{ Hospital type } \\
\hline District hospital & 11 & 13.60 & & \\
\hline $\begin{array}{ll}\text { District teaching } \\
\text { hospital }\end{array}$ & 12 & 14.80 & & \\
\hline Regional teaching hospita & 58 & 71.60 & & \\
\hline \multicolumn{5}{|l|}{$\begin{array}{l}\text { Major shift type over the } \\
\text { preceding half year }\end{array}$} \\
\hline Day shift & 9 & 11.10 & & \\
\hline Swing shift & 21 & 25.90 & & \\
\hline Night shift & 17 & 21.00 & & \\
\hline Rotational & 34 & 42.00 & & \\
\hline \multicolumn{5}{|l|}{ Number of shifts per week } \\
\hline Fixed & 64 & 79.00 & & \\
\hline Two & 13 & 16.05 & & \\
\hline Three & 4 & 4.95 & & \\
\hline \multicolumn{5}{|l|}{ In-service training } \\
\hline No & 74 & 91.40 & & \\
\hline Yes & 7 & 8.60 & & \\
\hline \multicolumn{5}{|l|}{$\begin{array}{l}\text { Part-time job (multiple answers } \\
\text { possible) }\end{array}$} \\
\hline Nurse & 81 & 100.0 & & \\
\hline Leader & 28 & 34.60 & & \\
\hline Clinical teacher & 11 & 13.60 & & \\
\hline \multicolumn{5}{|l|}{ Rank } \\
\hline N0 & 9 & 11.10 & & \\
\hline N1 & 13 & 16.10 & & \\
\hline N2 & 57 & 70.40 & & \\
\hline N3 & 1 & 1.20 & & \\
\hline $\mathrm{N} 4$ & 1 & 1.20 & & \\
\hline Self-rated present health status & & & 0.94 & 0.56 \\
\hline Not good & 14 & 17.30 & & \\
\hline Average & 59 & 72.90 & & \\
\hline Good & 7 & 8.60 & & \\
\hline Very good & 1 & 1.20 & & \\
\hline Health status now vs. 1 year ago & & & 1.15 & 0.73 \\
\hline Much worse & 14 & 17.30 & & \\
\hline
\end{tabular}




\begin{tabular}{|c|l|l|l|l|}
\hline Slightly worse & 43 & 53.10 & & \\
\hline Similar & 22 & 27.20 & & \\
\hline Better & 2 & 2.40 & & \\
\hline Other duties outside this division & & & & \\
\hline No & 66 & 81.50 & & \\
\hline Yes & 15 & 18.50 & & \\
\hline
\end{tabular}

Appendix B. Analysis of the Modulating Effect of Patient Illness Severity on Nurse socio-demographic characteristics and occupational stress

\begin{tabular}{|c|c|c|c|c|c|}
\hline \multirow[t]{2}{*}{$\begin{array}{l}\text { Modulating } \\
\text { variable }\end{array}$} & $\begin{array}{l}\text { Perso } \\
\text { nal } \\
\text { respo } \\
\text { nses }\end{array}$ & $\begin{array}{c}\text { Job } \\
\text { concerns }\end{array}$ & Competencies & $\begin{array}{c}\text { Inability to } \\
\text { complete } \\
\text { personal duties }\end{array}$ & $\begin{array}{l}\text { Total } \\
\text { occupational } \\
\text { stress score }\end{array}$ \\
\hline & $\begin{array}{c}\text { F- } \\
\text { value }\end{array}$ & F-value & F-value & F-value & F-value \\
\hline $\begin{array}{l}\text { Age* APACHE } \\
\text { II }\end{array}$ & $\begin{array}{c}9.08^{*} \\
*\end{array}$ & 41.59 *** & $16.97 * * *$ & 2.02 & $33.55^{* * *}$ \\
\hline $\begin{array}{c}\text { Educational } \\
\text { level* APACHE } \\
\text { II }\end{array}$ & .24 & $4.48 *$ & 2.30 & $14.10^{* * *}$ & .25 \\
\hline $\begin{array}{c}\text { Marital status* } \\
\text { APACHE II }\end{array}$ & $\begin{array}{c}33.92 \\
* * *\end{array}$ & $56.90 * * *$ & $33.04 * * *$ & $5.20 *$ & $78.42^{* * *}$ \\
\hline $\begin{array}{c}\text { Number of } \\
\text { patients* } \\
\text { APACHE II }\end{array}$ & $\begin{array}{c}24.68 \\
* * *\end{array}$ & $11.72 * * *$ & .31 & $8.93^{* *}$ & $26.92 * * *$ \\
\hline $\begin{array}{c}\text { ICU training* } \\
\text { APACHE II }\end{array}$ & $\begin{array}{c}28.59 \\
* * *\end{array}$ & .12 & $6.19 *$ & $48.33^{* * *}$ & $28.42^{* * *}$ \\
\hline $\begin{array}{c}\text { Job seniority* } \\
\text { APACHE II }\end{array}$ & $3.83 *$ & $16.23 * * *$ & $36.20 * * *$ & .66 & $20.06 * * *$ \\
\hline $\begin{array}{c}\text { ICU seniority* } \\
\text { APACHE II }\end{array}$ & $\begin{array}{c}6.91 * \\
*\end{array}$ & $24.81 * * *$ & $30.30 * * *$ & $4.59 *$ & $20.73^{* * *}$ \\
\hline $\begin{array}{c}\text { Employment } \\
\text { status* } \\
\text { APACHE II }\end{array}$ & .02 & $61.53 * * *$ & $28.49 * * *$ & $34.80 * * *$ & $9.21^{* *}$ \\
\hline $\begin{array}{c}\text { Hospital level* } \\
\text { APACHE II } \\
\end{array}$ & $\begin{array}{c}15.14 \\
* * *\end{array}$ & $64.45^{* * *}$ & $25.99 * * *$ & $5.85^{*}$ & $40.84^{* * *}$ \\
\hline $\begin{array}{c}\text { Shift type* } \\
\text { APACHE II }\end{array}$ & $\begin{array}{c}8.17 * \\
*\end{array}$ & .61 & 2.99 & 2.31 & $4.45^{*}$ \\
\hline $\begin{array}{c}\text { Ranking* } \\
\text { APACHE II } \\
\end{array}$ & .78 & $6.43 * *$ & $42.29 * * *$ & 2.64 & 2.72 \\
\hline $\begin{array}{l}\text { Current health } \\
\text { status* } \\
\text { APACHE II } \\
\end{array}$ & $\begin{array}{c}30.61 \\
* * *\end{array}$ & $46.48 * * *$ & $5.61 *$ & 1.21 & $54.32 * * *$ \\
\hline $\begin{array}{l}\text { Health status } \\
\text { previous year* } \\
\text { APACHE II }\end{array}$ & $\begin{array}{l}41.80 \\
* * *\end{array}$ & 36.36 *** & 2.19 & $5.63 *$ & $43.97 * * *$ \\
\hline
\end{tabular}

